\title{
Percepción de inseguridad, temor al delito y medidas de autoprotección: el caso de Acapulco, Guerrero
}

\author{
Perceived insecurity, fear of crime and \\ self-protection measures: the case of Acapulco, Guerrero
}

Jorge Luis Triana Sánchez ${ }^{1}$

Fecha de recepción: 8 de septiembre de 2020

Fecha de aceptación: 6 de enero de 2021 


\section{Resumen}

Se analizan los factores determinantes de la construcción subjetiva de la inseguridad y el temor ante la delincuencia, a partir de las teorías explicativas sobre victimización, vulnerabilidad física y social, incivilidades, y redes sociales. Se estiman modelos de regresión con datos de Acapulco, Guerrero, con el fin de evaluar el efecto de dichos factores sobre la percepción de inseguridad en entornos cotidianos, la modificación de actividades por temor al delito, y la implementación de medidas de autoprotección en la vivienda. Los resultados revelan que la prevalencia de conductas antisociales o delictivas en el entorno es el principal predictor de la percepción de inseguridad y el temor al delito entre las personas.

Palabras clave: seguridad ciudadana, victimización, desorden social, delincuencia, análisis cuantitativo.

\section{Abstract}

This paper analyzes the factors of the subjective construction of insecurity and fear of crime, based on theories about victimization, physical and social vulnerability, incivilities, and social networks. Regression models are estimated with data from Acapulco, Guerrero, in order to evaluate the effect of such factors on the perception of insecurity in everyday environments, the modification of activities due to fear of crime, and the implementation of self-protection measures at home. The results show that the prevalence of antisocial or criminal behaviors in the environment is the main predictor of perceived insecurity and fear of crime among people.

Keywords: citizen security, victimization, social disorder, crime, quantitative analysis. 


\section{Introducción}

$\mathrm{L}$

os estudios sobre seguridad ciudadana abordan la problemática criminal desde dos perspectivas: una objetiva, referente a la incidencia delictiva que efectivamente ocurre en una determinada sociedad, y otra subjetiva, que comprende elementos como la percepción de inseguridad y el temor al delito de las personas. Si bien los primeros estudios criminológicos centraron la atención en elementos objetivos como la actividad delincuencial y su impacto sobre las víctimas, con el tiempo quedó de manifiesto que el crimen también afectaba el bienestar, calidad de vida y relaciones interpersonales de la ciudadanía que no había sufrido algún delito, pero que percibía que podía ser victimizada en un futuro (Buil, 2016).

El componente subjetivo de la seguridad ciudadana ha sido conceptualizado de múltiples maneras en la literatura sobre el tema, encontrando investigaciones que lo abordan como percepción o sensación de inseguridad, percepción de peligro o de riesgo, alarma social, preocupación por la delincuencia, temor al delito o miedo al crimen, entre otras; a partir de diversos abordajes conceptuales y metodológicos, se le ha considerado como una emoción o sentimiento, una estructura cultural, o incluso una manifestación política (Jasso, 2013). No obstante, el denominador común en dichos estudios es la diferenciación entre la parte general y la específica de la construcción subjetiva del fenómeno; cuando se hace referencia a la parte general, suele utilizarse el término "percepción de inseguridad", mientras que la parte específica recurre al término "temor al delito".

Jasso $(2013$, pp. 16, 18) define la percepción de inseguridad como "un cálculo general de la situación prevaleciente de inseguridad", proceso en el cual "la persona se sitúa frente a las circunstancias y emite un juicio sobre las posibilidades de ser víctima de un delito". Kessler (2009, p. 35), por otro lado, afirma que es una "respuesta emocional a la percepción de símbolos relacionados con el delito". Al ser entonces un concepto sustentado en circunstancias, situaciones y símbolos, la percepción de inseguridad es un término que puede estudiarse en función de lugares o entornos concretos.

El miedo o temor al delito, en cambio, representa "un cálculo más específico sobre el riesgo de ser víctima de un delito" (Jasso, 2013, p.18), provocando una "perturbación angustiosa del ánimo" (Vilalta, 2010, p. 8) o una "respuesta emocional de nerviosismo o ansiedad al delito o símbolos que la persona asocia al delito" (Ferraro, 1995, p. 4). Así, el temor al delito puede estudiarse a través de las consecuencias sobre el comportamiento observable en las personas, principalmente "conductas de protección dentro y fuera del hogar, de tipo evitativo o activo" (Ruiz, 2007, p. 66).

En ambos casos, las personas realizan un cálculo de las posibilidades generales y específicas "a partir de la información disponible, ya sea desde los medios de comunicación, las conversaciones con sus vecinos, o lo que percibe en su entorno cotidiano" (Jasso, 2013, p. 18), de ahí que sentirse inseguros o temer al delito no sea exclusivo de las personas que han sido efectivamente victimizadas, ni de entornos con una alta incidencia delictiva (Föhrig, 2006; Vozmediano, Vergara y San Juan, 2010).

La percepción de inseguridad y temor al delito son fenómenos con implicaciones relevantes para la sociedad. En términos generales, provocan una afectación a la calidad de vida a través de la restricción voluntaria de actividades y movilidad de las personas, y el distanciamiento de los distintos sectores sociales (Hale, 1996; Kessler y Focás, 2014); también impactan la vida pública y el bienestar social al tras- 
tocar la convivencia comunitaria (Buil, 2016), las rutinas y hábitos de las personas, y su estado anímico (Vilalta, 2012). En términos específicos, promueven el apoyo a políticas de seguridad más punitivas, la deslegitimación de la justicia penal, la justicia por propia mano y la posesión de armas de fuego (Becerra y Trujano, 2011; Kessler y Focás, 2014); además, provocan el surgimiento tanto de zonas urbanas en abandono, como de complejos residenciales cerrados y ultra protegidos (Hale, 1996); incluso se han señalado efectos sobre el control sociopolítico de la ciudadanía y la promoción de prácticas autoritarias en entornos con instituciones democráticas endebles, toda vez que un aumento del sentimiento de inseguridad detona el desarrollo de la seguridad privada como industria altamente lucrativa, favoreciendo el intercambio desregulado de la información que genera mediante sus tecnologías de vigilancia, protección y seguimiento (Arteaga y Fuentes, 2009).

El interés por el componente subjetivo de la seguridad ciudadana es relativamente reciente, lo cual ha impulsado su investigación teórica y empírica desde diversas disciplinas científicas (Jasso, 2013), y su posicionamiento en la agenda política de distintas regiones (Buil, 2016). No obstante, no deja de ser una dimensión altamente compleja y difícil de cuantificar dentro de la seguridad ciudadana (Córdova, 2007), así como una de las áreas menos atendidas dentro de la política criminal (Vilalta, 2012).

Este trabajo se propone abordar tanto la parte general como la específica del componente subjetivo de la seguridad ciudadana. Por un lado, se busca analizar la percepción de inseguridad de las personas en entornos cotidianos, con el fin de identificar los lugares donde encuentran con mayor frecuencia aquellas circunstancias, situaciones o símbolos que les hacen calcular una mayor probabilidad de ser víctimas de algún delito; por otro lado, se abordan las consecuencias del temor al delito sobre su comportamiento, y que se pueden observar en la modificación de sus actividades cotidianas y la implementación de medidas de autoprotección en el hogar.

El presente estudio es de alcance explicativo, ya que se desea conocer no solamente los niveles de percepción de inseguridad y temor al delito, sino también identificar sus factores determinantes. Para tal efecto, se contrastan los factores que sugieren las teorías explicativas del fenómeno mediante un enfoque de investigación cuantitativo, utilizando datos de Acapulco, Guerrero, un caso paradigmático a nivel nacional en términos de criminalidad, inseguridad pública y violencia.

Si bien en la literatura se pueden encontrar estudios empíricos sobre el tema con cobertura nacional o estatal, son pocos los estudios desarrollados a nivel local; esto se debe principalmente a la disponibilidad de datos, pues la principal fuente de información en México sobre aspectos objetivos y subjetivos de la seguridad ciudadana es la Encuesta Nacional de Victimización y Percepción sobre Seguridad Pública (ENVIPE), misma que cuenta con levantamiento anual y representatividad a nivel nacional y estatal, y en menor medida la Encuesta Nacional de Seguridad Pública Urbana (ENSU), con periodicidad trimestral y representatividad a nivel nacional y urbano.

La escasez de datos locales ha dificultado el estudio de la percepción de inseguridad y temor al delito en locaciones específicas con circunstancias extremas de violencia criminal, como ha sido el caso reciente de Acapulco: de acuerdo con el ranking de ciudades más violentas del mundo elaborado por el Consejo Ciudadano para la Seguridad Pública y la Justicia Penal (CCSPJP), en el período 2011-2019 esta ciudad se mantuvo dentro de los primeros lugares, con sus peores registros en 2012 y 2016 cuando ocupó el segundo lugar, mientras que en 2019 se ubicó séptimo. Respecto al componente subjetivo de la inseguridad ciudadana, los datos de los últimos siete años de la ENSU muestran que 2017 y 2018 fueron los de mayor 
percepción de inseguridad en las zonas urbanas a nivel nacional; en dichos años, el porcentaje de población mayor de edad que consideraba que, en términos de delincuencia, era inseguro vivir en su ciudad, osciló entre 72.9 y $76.8 \%$, mientras que Acapulco se ubicó en promedio 11 puntos porcentuales encima de tales valores, con proporciones que fluctuaron entre 83.2 y $89 \%$. Esta anormalidad en dicho enclave geográfico ha sido abordada de manera incipiente en algunos estudios locales (Triana 2017; Salado et al., 2018; Basilio et al., 2019; Triana et al., 2019), pero solamente a un nivel descriptivo o correlacional, sin comprobar en términos empíricos las relaciones propuestas por las teorías que explican tal fenómeno.

El escenario objetivo y subjetivo de violencia y delincuencia en Acapulco ha motivado diversos esfuerzos desde el sector académico para recolectar datos sobre seguridad ciudadana; particularmente, en este trabajo se utiliza la Encuesta sobre Seguridad Ciudadana en Acapulco (ESCA), misma que fue levantada en 2019 y que utilizó un muestreo probabilístico, por lo cual dicha base resulta apropiada para la implementación de técnicas de análisis cuantitativo que permitan comprobar la significancia estadística de los factores que determinan la percepción de inseguridad y el temor al delito, según sugieren las teorías que se exponen en la siguiente sección.

\section{Factores determinantes de la percepción de inseguridad y el temor al delito}

Existen cinco teorías explicativas de la inseguridad y temor al delito, las cuales proponen la construcción subjetiva del fenómeno a partir de factores determinantes relativos a la victimización, vulnerabilidad física, vulnerabilidad social, expresiones de incivilidad y redes sociales (Vilalta, 2012).

La teoría de la victimización postula que la experiencia de sufrir un delito induce una mayor percepción de inseguridad; dicha experiencia puede ser directa o indirecta, es decir, puede referir a la victimización personal pero también a la de familiares, vecinos, amigos o conocidos, quienes al socializar el episodio delictivo sufrido inducen temor en otras personas; las personas también toman conocimiento de la actividad delictiva ajena a través de los medios de comunicación, aunque este mecanismo está sujeto a sus hábitos de consumo de información. (Hale, 1996; Vilalta, 2012; Buil, 2016)

La teoría de la vulnerabilidad física, por otro lado, sugiere que el sentirse inseguro o temeroso del delito depende de la capacidad percibida de las personas para protegerse a sí mismas, a partir de la fuerza, destrezas o habilidades que disponen ante una agresión; bajo esta teoría, las personas físicamente indefensas o desvalidas tendrán un mayor temor a ser víctimas de algún delito, sugiriendo que ciertos grupos sociales son más propensos a sentirse inseguros, como las mujeres, personas mayores o con alguna discapacidad. (Hale, 1996; Dammert, 2007; Vilalta, 2012; Buil, 2016)

La teoría de la vulnerabilidad social, en consonancia con la vulnerabilidad física, propone que efectivamente las personas más vulnerables son más propensas a sentirse inseguras y temerosas del delito, pero no por la falta de control material durante el episodio delictivo, sino por la exposición continuada al riesgo del mismo y la gravedad de sus consecuencias; de este modo, la vulnerabilidad refiere a elementos sociales que conforman grupos con menor capacidad de recuperación de las consecuencias de un delito, o bien con menor capacidad para prevenirlo; así, la percepción de inseguridad y el temor al delito sería mayor en personas de bajo nivel socioeconómico, menores niveles de educación, personas en condición 
de indigencia o minorías étnicas, así como en grupos ocupacionales con mayor exposición a la violencia criminal. (Hale, 1996; Vilalta, 2012; Buil, 2016)

En la teoría de las incivilidades se introducen nociones de diseño urbano y caracterizaciones sociodemográficas para explicar la percepción de inseguridad y temor al delito en un lugar determinado; en este sentido, la interacción entre las personas y un entorno urbano deteriorado configuran una percepción de desorden o incivilidad que aproxima el nivel de criminalidad en el mismo; algunos elementos del entorno que pudieran detonar sentirse inseguros son los lugares oscuros o pobremente iluminados, espacios solitarios, edificaciones descuidadas o en abandono, infraestructura urbana deteriorada, ausencia o deficiencia de vigilancia policial, desconfianza en las instituciones de seguridad y justicia, acumulación de basura en la vía pública, vandalismo, grafitis, pandillas, personas en estado de intoxicación por alcohol o drogas, prostitución, vecinos ruidosos o presencia de vagabundos; otros elementos que también inciden bajo esta teoría son el cambio poblacional acelerado, o una reputación de 'barrio duro' (Vilalta, 2012; Buil, 2016). Hunter (1978) incluso ha postulado que la incivilidad y el crimen están correlacionados con el concepto más general de desorden social, y que además la incivilidad tiene un impacto mayor sobre el temor al delito que la criminalidad misma. Es decir, el temor al delito deriva en mayor medida de experiencias de incivilidad que de la propia victimización.

Finalmente, bajo la teoría de redes sociales la percepción de inseguridad y temor al delito encuentran explicación en el apoyo que se da entre los miembros de una comunidad; así, aquellos colectivos con mayor confianza interpersonal, que alcanzan mayores vínculos sociales, y que por tanto cuentan con un mayor apoyo social, presentan menores niveles de inseguridad y temor; este efecto es producto de una mejora en la comunicación y cohesión comunitaria, que deriva en mejores recursos disponibles para la prevención y contención de la delincuencia, lo cual se traduce en última instancia en que los integrantes de la red se sientan seguros. (Vilalta, 2012; Buil, 2016)

En conjunto, estas teorías explicativas señalan que el fenómeno bajo estudio se encuentra sujeto a determinantes relacionados con la victimización (directa e indirecta), vulnerabilidad física (edad, sexo, condición de discapacidad), vulnerabilidad social (pobreza, marginación, bajo nivel educativo, condición étnica, ocupación), incivilidades (confianza institucional, deterioro de imagen urbana, conductas antisociales o delictivas en el entorno), y redes sociales (cohesión social, confianza interpersonal). Así, en el presente trabajo estas cinco teorías serán adoptadas de manera integral para el análisis de la percepción de inseguridad y temor al delito en el enclave geográfico local de interés; no obstante, es importante mencionar que existen tipologías alternativas como la de Vozmediano, San Juan y Vergara (2008) o Carro et al. (2010), que agrupan los factores determinantes en atributos personales, sociales y ambientales; o bien la clasificación de Varela y Schwaderer (2010), que consideran variables independientes en cinco dimensiones: territoriales, sociodemográficas, de autocuidado, evaluación de autoridades y victimización.

Los estudios empíricos en México han contrastado en reiteradas ocasiones las relaciones propuestas por los marcos teóricos enunciados; por ejemplo, el trabajo de Vilalta (2010) analiza la percepción de inseguridad en el área metropolitana de la Ciudad de México mediante un modelo de regresión ordinal, en función de factores individuales, familiares y del contexto comunitario, encontrando que las variables que predicen significativamente el fenómeno son la victimización directa, la confianza en la policía local y el contenido de los noticiarios; en otro estudio, Vilalta (2012) somete a comprobación las cinco teorías sobre percepción de inseguridad y temor al delito de manera simultánea, mediante una formulación 
matemática multivariada con datos a nivel nacional y del área metropolitana de la Ciudad de México, encontrando evidencia estadísticamente significativa que soporta las cinco teorías consideradas.

El trabajo descriptivo de Jasso (2013) revisa datos nacionales y determina que los espacios donde las personas se sienten más inseguras son el cajero automático en la vía pública, el banco y el transporte público, mientras que las actividades cotidianas que han dejado de hacer por temor a ser víctimas son: usar joyas, permitir que sus hijos menores salieran, y salir de noche; por otro lado, encuentra que el conocimiento de intervenciones públicas en materia de seguridad ciudadana no incide en la percepción de inseguridad de las personas.

El estudio de Ávila et al. (2015) analiza el miedo al delito, la implementación de medidas de autoprotección y modificación de actividades cotidianas en habitantes del Estado de México, encontrando que la victimización es un factor altamente asociado a dichas variables, y que se presenta de manera más intensa en hombres que en mujeres; un estudio posterior de Ávila et al. (2016), ahora con datos del estado de Morelos, replica el papel protagónico de la victimización en hombres, un resultado particular que apoya la teoría de la victimización pero contraviene la teoría de la vulnerabilidad física, según la cual las mujeres deberían tener mayor percepción de inseguridad y temor al delito. Los autores explican estos resultados como consecuencia del rol protagónico de los hombres en sus familias y comunidades, pues al ser responsables de la seguridad y protección de sus integrantes, procuran un mayor acceso a la información sobre violencia y seguridad pública.

La investigación de Martínez-Ferrer et al. (2016), con datos del estado de Morelos, revela que haber sido víctima de algún delito, sentirse inseguro en espacios públicos, y adoptar medidas de protección física, son elementos asociados con un bajo nivel de satisfacción con la vida.

El trabajo de Galeana (2018), mediante una metodología mixta (observación, entrevistas y encuestas) en el estado de Veracruz, explica la percepción de inseguridad de habitantes de conjuntos habitacionales de interés social a partir de las dimensiones morfológica, urbanística, arquitectónica y social; los factores que inciden en la construcción de la percepción de inseguridad en estos lugares son las condiciones precarias de la vivienda y del espacio público, así como la deficiencia en la provisión de servicios básicos.

Finalmente, el estudio de Singer et al. (2019) revisa datos de México, Estados Unidos, Argentina y Brasil, y encuentra una asociación entre el temor al delito y la confianza en las instituciones del sistema de justicia penal.

Los factores determinantes de la percepción de inseguridad y el temor al delito que sugieren tanto las bases teóricas como los fundamentos empíricos presentes en estudios realizados en México, fueron observados mediante diversos ítems de la ESCA 2019; en la siguiente sección, se expone la estrategia metodológica para conducir el análisis de dicha información.

\section{Metodología}

La ESCA 2019 fue levantada en hogares de siete colonias o barrios del área urbana del municipio de Acapulco (Ejido, La Sabana, Petaquillas, Renacimiento, Zapata, Progreso y Jardín), las cuales son zonas predominantemente habitacionales, con muy poca edificación vertical y fuera de la zona turística del puerto. El muestreo de la encuesta considera el universo de viviendas habitadas en estas co- 
lonias $(\mathrm{N}=24,958)$ para estimar, bajo una técnica aleatoria simple, la proporción de personas mayores de 18 años que en los últimos 12 meses fue víctima de algún delito, tomando como referencia un valor $\mathrm{p}=0.137$, un nivel de confianza del $95 \%$ y un error de estimación de $\pm 1.5 \%$; con tales parámetros, se obtiene un tamaño de muestra $n=1,876$, la cual fue distribuida en cada colonia a partir de su peso relativo por el número de habitantes, introduciendo la aleatoriedad mediante saltos sistemáticos de las viviendas encuestadas. La encuesta se realizó los domingos 19 y 26 de mayo de 2019, entre las ocho de la mañana y seis de la tarde. ${ }^{2}$ (Triana et al., 2019)

En la ESCA 2019 se disponen de diversos ítems que pueden aproximar el fenómeno de la percepción de inseguridad y temor al delito. Al respecto, en la literatura se ha advertido que dichos fenómenos no han sido definidos con suficiente claridad, que en términos metodológicos es muy complicado medirlos con una sola pregunta en una encuesta, y que incluso es recomendable el uso de varias preguntas relacionadas (Vozmediano, 2010; Vilalta, 2012); Ferraro y LaGrange (1987) señalan que es recomendable que los ítems para su medición refieran de manera específica al miedo que sufren la personas y no a su preocupación por el problema, que se especifique que dicho miedo sea producto de la delincuencia, y que se cuestione de manera directa.

Considerando lo anterior, en este trabajo se utilizarán como variables dependientes: 1) la percepción de inseguridad acumulada, que considera el número de entornos cotidianos en los cuales la persona encuestada se siente insegura en términos de delincuencia; 2) el temor al delito acumulado, que representa el número de comportamientos cotidianos que la persona encuestada ha modificado por temor a ser víctima de un delito; y 3) el conjunto de medidas de autoprotección en el hogar, que contabiliza las medidas implementadas en la vivienda para protegerse de la delincuencia. El primer elemento, al referir a la percepción de inseguridad en lugares o entornos específicos, captura la parte general de la construcción subjetiva del fenómeno, mientras que el segundo y tercer elemento, al observar consecuencias sobre el comportamiento (en el individuo y en su vivienda), captura la parte específica.

A partir de los ítems disponibles en la ESCA 2019, se propone una relación funcional en la cual dichas variables dependientes son determinadas por un conjunto de variables independientes relativas a la victimización (directa e indirecta), vulnerabilidad física (edad, sexo), vulnerabilidad social (ingreso, marginación, educación, auto adscripción indígena o afrodescendiente, hogares con jefa de familia), expresiones de incivilidades en su entorno (deterioro de imagen urbana, conductas antisociales o delictivas, confianza institucional), y la composición de redes sociales (cohesión social, confianza interpersonal). En el anexo 1 se detalla la construcción y codificación de las variables.

Como técnica de análisis se propone realizar, para cada variable dependiente, una regresión lineal múltiple que evalúe la significancia estadística de cada factor determinante, con el fin de comprobar los efectos hipotetizados a partir de las cinco teorías tomadas en consideración y que se muestran en el cuadro 1; las variables con coeficiente positivo son aquellas que se espera que aumenten la percepción de inseguridad y el temor al delito, mientras que aquellas con signo negativo serían los atributos que provocan su disminución.

2- La base de datos de la ESCA 2019 se encuentra disponible en la siguiente dirección: https://doi.org/ 10.5281/zenodo. 4338682 


\begin{tabular}{|c|c|}
\hline Variable & $\begin{array}{l}\text { Efecto sobre la percepción de } \\
\text { inseguridad y temor al delito }\end{array}$ \\
\hline Victimización directa & Positivo \\
\hline Victimización indirecta & Positivo \\
\hline Edad & Positivo \\
\hline Sexo (hombre) & Negativo \\
\hline Ingreso & Negativo \\
\hline $\begin{array}{l}\text { Grado de marginación (la vivienda cuenta con piso de tierra, paredes de lámi- } \\
\text { na/cartón, adobe o material de desecho, o techo de lámina/cartón o material } \\
\text { de desecho) }\end{array}$ & Positivo \\
\hline Nivel educativo & Negativo \\
\hline Auto adscripción indígena & Positivo \\
\hline Auto adscripción afrodescendiente & Positivo \\
\hline Hogar con mujer jefa de familia & Positivo \\
\hline Deterioro de imagen urbana & Positivo \\
\hline Conductas antisociales o delictivas & Positivo \\
\hline Cohesión social & Negativo \\
\hline Confianza institucional & Negativo \\
\hline Confianza interpersonal & Negativo \\
\hline
\end{tabular}

Fuente: Elaboración propia

\section{Resultados}

Como introducción al estudio de la percepción de inseguridad y temor al delito, así como sus factores determinantes, se presenta la estadística descriptiva de las variables utilizadas. En la gráfica 1 se pueden apreciar los entornos cotidianos en los cuales las personas encuestadas se sienten más inseguras, destacando el cajero automático ubicado en la calle, el transporte público y la carretera, mientras que los lugares en los cuales se sienten más seguros son la casa, el trabajo y la escuela, resultados que coinciden con mediciones de otros estudios locales y nacionales (Jasso, 2013; Centro de Estudios Sociales y de Opinión Pública, 2017; Triana, 2017). Si se analiza la variable acumulada (cuadro 2), se puede afirmar que en promedio una persona se siente insegura en aproximadamente ocho lugares de los 12 cuestionados. 


\section{Percepción de inseguridad en entornos cotidianos}

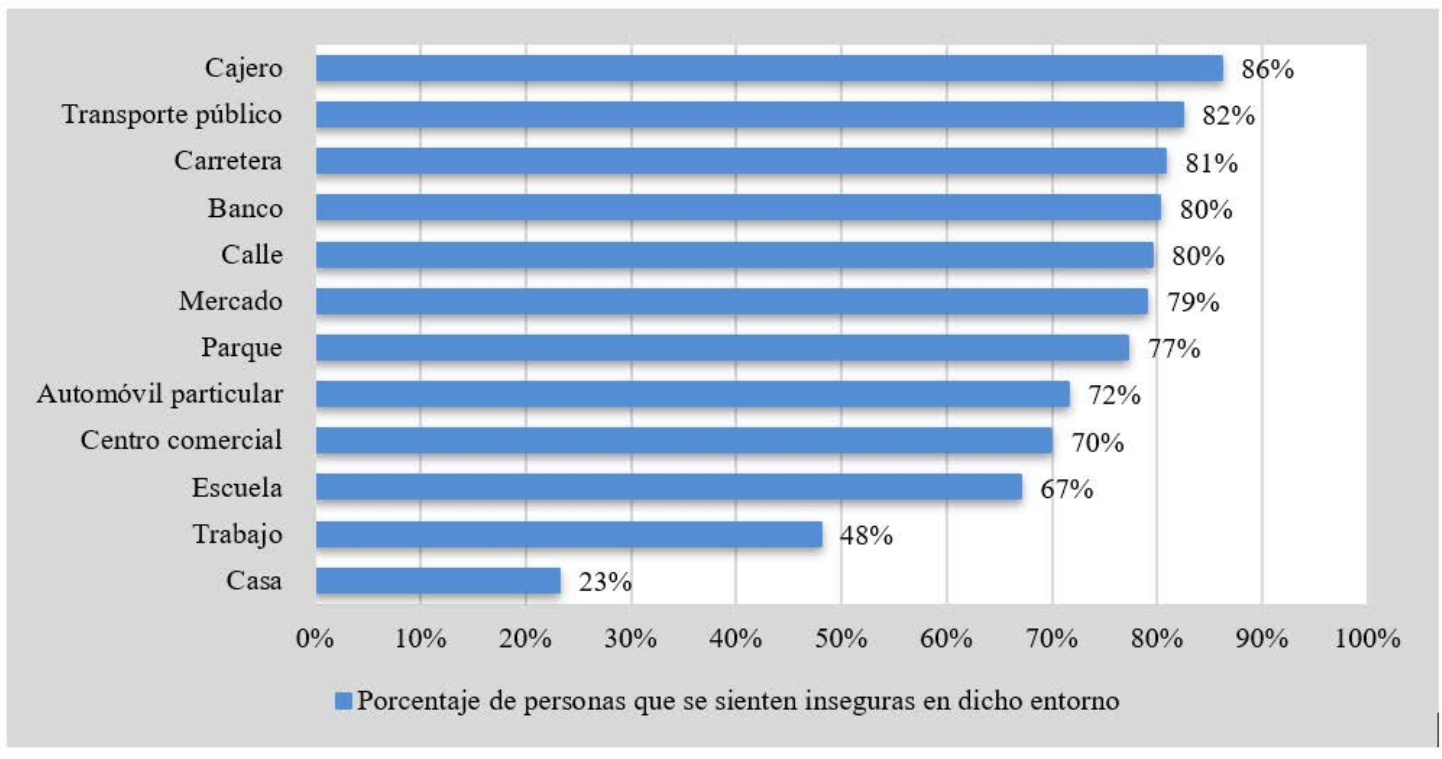

Fuente: Elaboración propia con datos de la ESCA 2019

La gráfica 2 muestra la modificación de comportamientos cotidianos por temor a ser víctimas de un delito, donde se destacan salir de noche, permitir que los menores salgan solos, y usar joyas, como los cambios realizados con mayor frecuencia; mientras que los de menor incidencia fueron tomar taxi o transporte público, e ir a la escuela. En términos acumulados, los encuestados incurrieron en casi seis modificaciones en promedio, de las 15 enunciadas en la encuesta. 


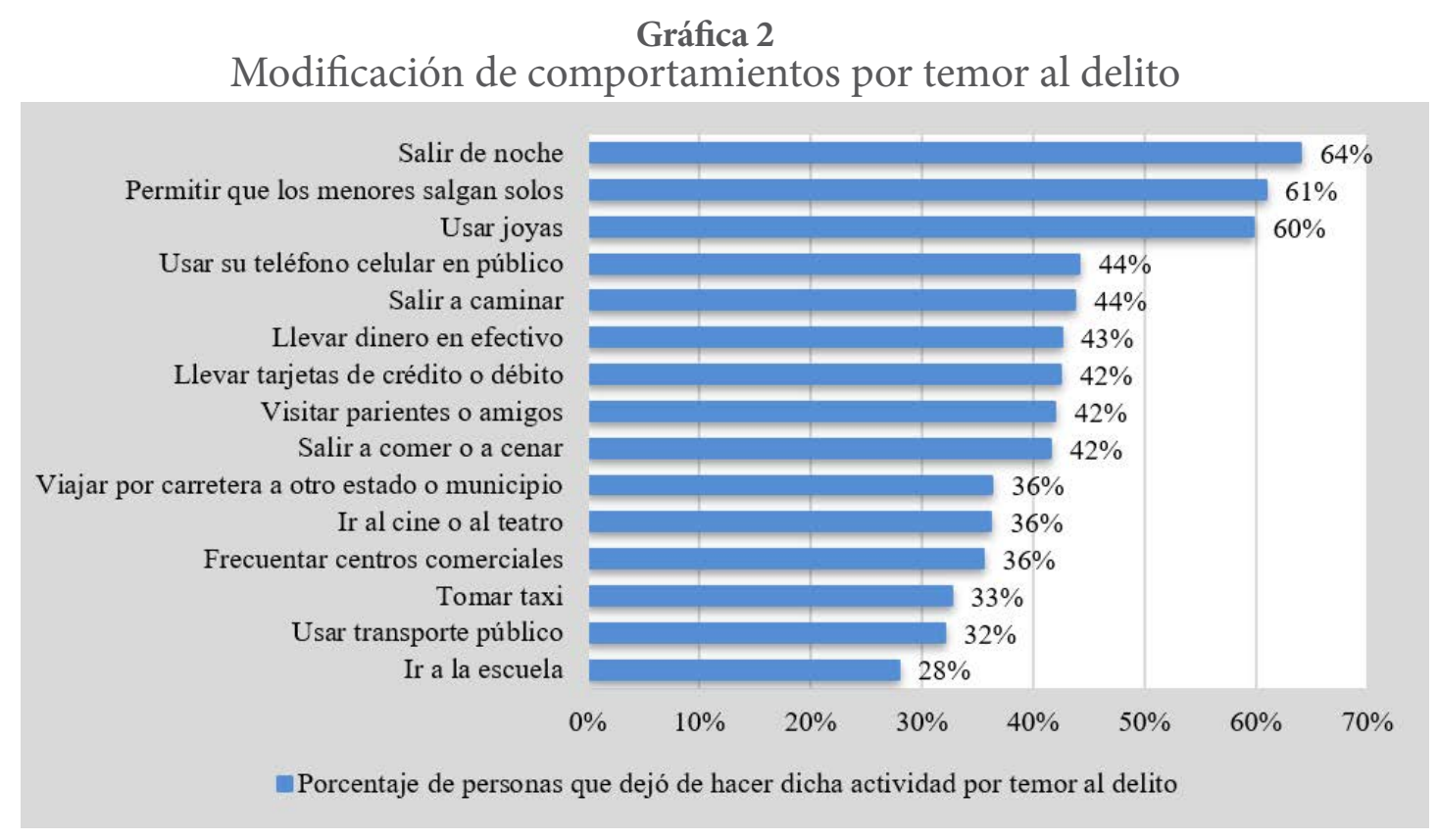

Fuente: Elaboración propia con datos de la ESCA 2019

Respecto a las medidas de autoprotección implementadas en el hogar debido a la delincuencia (gráfica 3), las de mayor frecuencia tienen que ver con el reforzamiento de las medidas de resguardo físico de la vivienda, como puertas, ventanas, cerraduras, candados, rejas o bardas. Mientras que las medidas menos usadas fueron cambiarse de vivienda, contratar vigilancia privada y adquirir un arma de fuego. Si bien cada vivienda encuestada implementó en promedio una medida de autoprotección, la desviación típica revela que esta variable se encuentra demasiado dispersa (cuadro 2); de hecho, el 64\% de los encuestados respondió no haber realizado ninguna de las medidas enlistadas. Esta particularidad de la variable podría representar un problema en términos de estimación, ya que la gran cantidad de observaciones con valor de cero no necesariamente significa que la vivienda no haya implementado ninguna medida de protección, sino que tal vez la persona encuestada no sabía que dicha medida fue realizada. En tales circunstancias, una regresión lineal múltiple estimada por mínimos cuadrados ordinarios (MCO) genera coeficientes sesgados, debiendo utilizarse en cambio una regresión tipo Tobit, estimada mediante un método de máxima verosimilitud (MV) (Wooldridge, 2015, p. 597). 


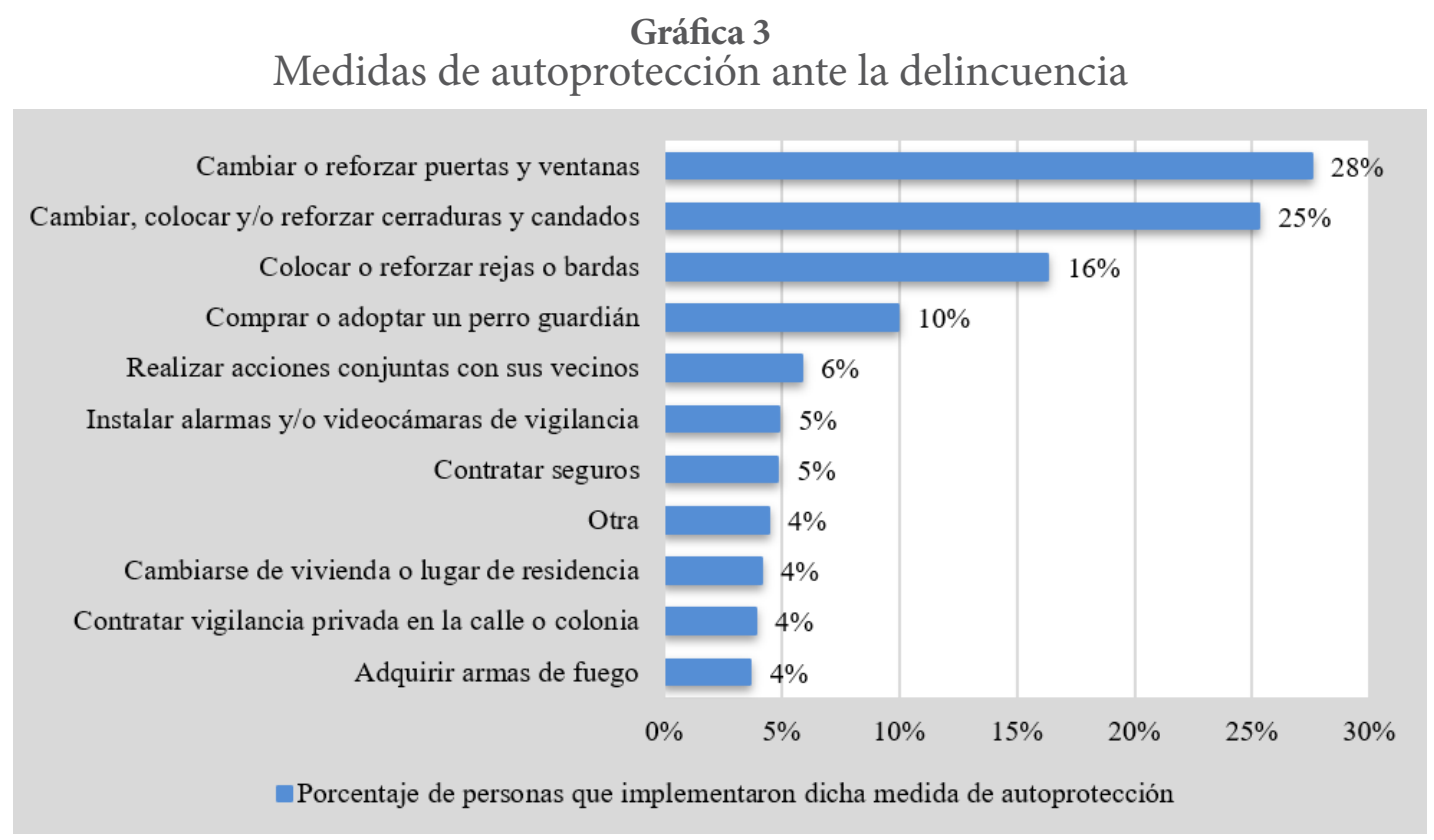

Fuente: Elaboración propia con datos de la ESCA 2019

El cuadro 2 muestra también la estadística descriptiva de las variables independientes utilizadas. En términos sociodemográficos, la muestra analizada se compone de personas con una edad promedio de 47 años, una presencia de $44 \%$ de hombres, un ingreso mensual per cápita promedio de entre $\$ 1,201$ y $\$ 1,800$, y un nivel educativo promedio equivalente a secundaria; una cuarta parte reveló al menos una condición de marginación en el piso, paredes o techo de la vivienda, mientras que el 27\% se auto adscribió como indígena y un 14\% como afrodescendiente; además, uno de cada cinco hogares cuenta con jefatura de hogar femenina.

Respecto a los niveles de victimización directa e indirecta en los últimos 12 meses, cerca del 11\% de los encuestados reportó haber sido víctima de algún delito, mientras que el 17\% tuvo conocimiento de la ocurrencia de algún delito en un familiar, 15\% en algún vecino, y $20 \%$ en algún amigo o conocido. Por otro lado, la muestra registró un promedio de cuatro elementos de deterioro de imagen urbana (de los nueve enunciados), siendo los más mencionados la presencia de perros callejeros y las casas o edificios abandonados; en conductas antisociales o delictivas en el entorno se obtuvo un promedio de cinco (de las 15 enunciadas), siendo las más frecuentes el consumo de alcohol en la calle y el escuchar disparos de arma de fuego.

Finalmente, de las variables medidas en escalas tipo Likert, la cohesión social tuvo un valor medio de 1.7, donde los motivos más frecuentes para reunirse con sus vecinos fueron organizar fiestas y solucionar problemas relativos a servicios públicos; la confianza institucional promedió 2.1, siendo la marina y el ejército los de mejor puntuación, mientras que la confianza interpersonal media fue de 2.9, donde las personas de mayor confianza fueron sus familiares y amigos. 
Cuadro 2

\begin{tabular}{|c|c|c|c|c|}
\hline \multicolumn{1}{|c}{ Estadística descriptiva } \\
\hline Variable & Media & Desv. Típica & Mín. & Máx. \\
\hline Percepción de inseguridad acumulada & 7.63 & 3.57 & 0 & 12 \\
\hline Temor al delito acumulado & 5.68 & 4.75 & 0 & 15 \\
\hline Conjunto de medidas de autoprotección & 1.05 & 1.85 & 0 & 11 \\
\hline Victimización directa & 0.107 & 0.309 & 0 & 1 \\
\hline Victimización indirecta en familiares & 0.167 & 0.373 & 0 & 1 \\
\hline Victimización indirecta en vecinos & 0.151 & 0.358 & 0 & 1 \\
\hline Victimización indirecta en amigos o conocidos & 0.203 & 0.402 & 0 & 1 \\
\hline Edad & 47.1 & 17.7 & 18 & 98 \\
\hline Sexo & 0.444 & 0.497 & 0 & 1 \\
\hline Confianza interpersonal & 2.85 & 1.58 & 1 & 6 \\
\hline Ingreso per cápita estimado en la vivienda & 0.254 & 0.435 & 0 & 1 \\
\hline Grado de marginación & 3.28 & 1.27 & 1 & 5 \\
\hline Nivel educativo & 0.270 & 0.444 & 0 & 1 \\
\hline Auto adscripción indígena & 0.136 & 0.343 & 0 & 1 \\
\hline Auto adscripción afrodescendiente & 0.201 & 0.401 & 0 & 1 \\
\hline Hogar con jefa de familia & 4.19 & 3.04 & 0 & 9 \\
\hline Deterioro de imagen urbana & 4.73 & 4.32 & 0 & 15 \\
\hline Conductas antisociales o delictivas en el entorno & 1.77 & 0.79 & 1 & 5 \\
\hline Grado de cohesión social & 2.13 & 0.81 & 1 & 5 \\
\hline Confianza institucional & 2.91 & 0.98 & 1 & 5 \\
\hline
\end{tabular}

Fuente: Elaboración propia con datos de la ESCA 2019

En el cuadro 3 se presentan los resultados de regresión de los modelos propuestos; los modelos 1 y 2 son regresiones lineales múltiples estimadas mediante MCO, y el modelo 3 es una regresión tipo Tobit estimada mediante MV. Es importante aclarar que, debido a valores perdidos en algunas de las variables utilizadas (principalmente el ingreso), el número de observaciones consideradas en la estimación es de solamente 1,436 en los tres modelos.

En el primer modelo, solamente el sexo, las conductas antisociales o delictivas, y la confianza institucional e interpersonal resultaron estadísticamente significativas (considerando un nivel de significancia del 5\%); en dichas variables el signo obtenido fue el esperado, tal que se puede afirmar que la percepción de inseguridad es mayor en mujeres, en personas con baja confianza en las instituciones, con baja confianza interpersonal, y que presentan mayor prevalencia de conductas antisociales o delictivas en su entorno. Es decir, la percepción de inseguridad (parte general del componente subjetivo de la seguridad 
ciudadana) es un fenómeno explicado por elementos relativos a la vulnerabilidad física, la prevalencia de incivilidades y la configuración de las redes sociales, mientras que la victimización y la vulnerabilidad social no parecen tener efectos sustanciales.

En el segundo modelo, las variables estadísticamente significativas fueron la victimización directa, edad, sexo, ingreso, hogares con jefa de familia, deterioro de la imagen urbana, y las conductas antisociales o delictivas; igualmente en este modelo el efecto de dichas variables es acorde al esperado, por lo que se puede afirmar que el temor al delito es mayor entre quienes fueron víctimas de manera directa, personas mayores, mujeres, con niveles bajos de ingreso, en hogares con jefa de familia, en colonias con una imagen urbana deteriorada, y con conductas antisociales o delictivas en el entorno. Ahora, al evaluar el temor al delito (parte específica del componente subjetivo de la seguridad ciudadana) se encuentran elementos determinantes relacionados con la victimización, vulnerabilidad física, vulnerabilidad social, incivilidades y redes sociales.

El tercer modelo encuentra como variables estadísticamente significativas a la victimización directa e indirecta (familiares y amigos), y a las conductas antisociales o delictivas en el entorno, igualmente con los signos esperados. Es notable que este sea el único modelo en el cual el sexo no es significativo, pero es un resultado coherente, ya que la variable dependiente hace referencia a medidas de autoprotección en la vivienda y no en la persona encuestada, tal que resulta irrelevante para la medición del atributo si quien respondió es hombre o mujer.

Cuadro 3

Resultados de regresión de modelos propuestos

\begin{tabular}{|c|c|c|c|}
\hline & $\begin{array}{l}\text { Modelo } 1 \\
\text { Percepción de inse- } \\
\text { guridad acumulada }\end{array}$ & $\begin{array}{l}\text { Modelo } 2 \\
\text { Temor al delito } \\
\text { acumulado }\end{array}$ & $\begin{array}{c}\text { Modelo } 3 \\
\text { Conjunto de medi- } \\
\text { das de autoprotec- } \\
\text { ción }\end{array}$ \\
\hline R-cuadrada & 0.1120 & 0.1360 & 0.1200 \\
\hline Prueba F & $\begin{array}{c}8.51 \\
(0.000)\end{array}$ & $\begin{array}{c}15.23 \\
(0.000)\end{array}$ & - \\
\hline Prueba Chi cuadrada & - & - & $\begin{array}{c}183.58 \\
(0.000)\end{array}$ \\
\hline \multicolumn{4}{|l|}{ Variables independientes } \\
\hline Victimización directa & $\begin{array}{c}0.2955 \\
(0.280)\end{array}$ & $\begin{array}{c}1.8922 \\
(0.000)\end{array}$ & $\begin{array}{c}0.8638 \\
(0.000)\end{array}$ \\
\hline Victimización indirecta en familiares & $\begin{array}{r}0.4030 \\
(0.086) \\
\end{array}$ & $\begin{array}{c}0.6204 \\
(0.059) \\
\end{array}$ & $\begin{array}{c}0.6487 \\
(0.000) \\
\end{array}$ \\
\hline Victimización indirecta en vecinos & $\begin{array}{r}-0.2537 \\
(0.367)\end{array}$ & $\begin{array}{r}0.5869 \\
(0.099)\end{array}$ & $\begin{array}{c}0.0174 \\
(0.906)\end{array}$ \\
\hline Victimización indirecta en amigos o conocidos & $\begin{array}{l}-0.3204 \\
(0.197) \\
\end{array}$ & $\begin{array}{c}0.2296 \\
(0.455)\end{array}$ & $\begin{array}{c}0.3136 \\
(0.018)\end{array}$ \\
\hline Edad & $\begin{array}{l}-0.0090 \\
(0.121) \\
\end{array}$ & $\begin{array}{c}0.0403 \\
(0.000)\end{array}$ & $\begin{array}{r}0.0045 \\
(0.121) \\
\end{array}$ \\
\hline Sexo & $\begin{array}{r}-0.5455 \\
(0.003)\end{array}$ & $\begin{array}{r}-1.5012 \\
(0.000)\end{array}$ & $\begin{array}{l}-0.0580 \\
(0.547)\end{array}$ \\
\hline
\end{tabular}




\begin{tabular}{|c|c|c|c|}
\hline Ingreso per cápita estimado en la vivienda & $\begin{array}{l}-0.0242 \\
(0.679)\end{array}$ & $\begin{array}{l}-0.1824 \\
(0.020)\end{array}$ & $\begin{array}{l}0.0388 \\
(0.195)\end{array}$ \\
\hline Grado de marginación & $\begin{array}{l}-0.2447 \\
(0.217)\end{array}$ & $\begin{array}{l}-0.5238 \\
(0.051)\end{array}$ & $\begin{array}{l}0.0082 \\
(0.938)\end{array}$ \\
\hline Nivel educativo & $\begin{array}{l}0.1154 \\
(0.175)\end{array}$ & $\begin{array}{l}0.1799 \\
(0.098)\end{array}$ & $\begin{array}{l}0.0377 \\
(0.364)\end{array}$ \\
\hline Auto adscripción indígena & $\begin{array}{l}0.0671 \\
(0.751)\end{array}$ & $\begin{array}{l}0.4154 \\
(0.151)\end{array}$ & $\begin{array}{l}0.1151 \\
(0.293)\end{array}$ \\
\hline Auto adscripción afrodescendiente & $\begin{array}{l}-0.2073 \\
(0.440)\end{array}$ & $\begin{array}{l}0.2392 \\
(0.508)\end{array}$ & $\begin{array}{l}-0.0782 \\
(0.571)\end{array}$ \\
\hline Hogar con jefa de familia & $\begin{array}{l}-0.3928 \\
(0.085)\end{array}$ & $\begin{array}{l}-0.7855 \\
(0.012)\end{array}$ & $\begin{array}{l}-0.1012 \\
(0.400)\end{array}$ \\
\hline Deterioro de imagen urbana & $\begin{array}{l}-0.0618 \\
(0.055)\end{array}$ & $\begin{array}{l}0.1272 \\
(0.008)\end{array}$ & $\begin{array}{l}0.0312 \\
(0.060)\end{array}$ \\
\hline $\begin{array}{c}\text { Conductas antisociales o delictivas en el } \\
\text { entorno }\end{array}$ & $\begin{array}{l}0.0952 \\
(0.000)\end{array}$ & $\begin{array}{l}0.1937 \\
(0.000)\end{array}$ & $\begin{array}{c}0.0508 \\
(0.000)\end{array}$ \\
\hline Grado de cohesión social & $\begin{array}{c}0.0394 \\
(0.722)\end{array}$ & $\begin{array}{l}-0.1529 \\
(0.310)\end{array}$ & $\begin{array}{c}0.1066 \\
(0.069)\end{array}$ \\
\hline Confianza institucional & $\begin{array}{r}-0.7922 \\
(0.000)\end{array}$ & $\begin{array}{r}-0.0051 \\
(0.975)\end{array}$ & $\begin{array}{r}-0.0658 \\
(0.280)\end{array}$ \\
\hline Confianza interpersonal & $\begin{array}{r}-0.4708 \\
(0.000)\end{array}$ & $\begin{array}{r}-0.1973 \\
(0.159)\end{array}$ & $\begin{array}{r}-0.0367 \\
(0.474)\end{array}$ \\
\hline Constante & $\begin{array}{l}11.1190 \\
(0.000)\end{array}$ & $\begin{array}{c}3.4174 \\
(0.000)\end{array}$ & $\begin{array}{c}0.0267 \\
(0.927)\end{array}$ \\
\hline
\end{tabular}

Fuente: elaboración propia; estimaciones en Stata 15 con datos de la ESCA 2019; n=1,436; se utilizan errores estándar robustos; p-valores entre paréntesis

El hecho de que las variables estadísticamente significativas sean diferentes en cada modelo confirma las preocupaciones de Vozmediano (2010) y Vilalta (2012), respecto a la dificultad para definir conceptual y operacionalmente el fenómeno bajo estudio. Si bien las cinco teorías explicativas de la percepción de inseguridad y temor al delito exponen factores determinantes con un sustento conceptual, la comprobación empírica depende de la operacionalización de la variable dependiente. Los resultados sugieren que la victimización directa, por ejemplo, es relevante para explicar los cambios específicos en el comportamiento individual de las personas y en las medidas de autoprotección que instaura en el hogar, pero la victimización indirecta solo afecta a esta última. La vulnerabilidad física predice una mayor percepción de inseguridad y temor al delito en las mujeres, mientras que la vulnerabilidad social solo afecta al temor al delito en personas con bajos niveles de ingreso y que viven en hogares con jefa de familia (aunque con un signo contrario al esperado, según la teoría de la vulnerabilidad social). Las expresiones de incivilidades son las que parecen determinar de manera más contundente la construcción subjetiva de inseguridad y temor, y en particular las conductas antisociales o delictivas presentes en el entorno; el deterioro de la imagen urbana, por otro lado, solo afecta al temor al delito de manera individual. Finalmente, la teoría de redes sociales no tuvo evidencia a su favor en términos de la cohesión social de los encuestados, solamente respecto a la confianza interpersonal que sí tiene un efecto significativo para reducir la percepción de inseguridad. 
Los hallazgos del presente estudio permiten ahondar en la comprensión de la percepción de inseguridad y temor al delito a través de dos vías: 1) el contraste de los resultados con otros antecedentes empíricos en la materia; y 2) su discusión a la luz de las cinco teorías expuestas. Es importante recordar que los modelos propuestos fueron estimados con datos locales de un entorno urbano con altos índices de violencia y delincuencia, así como niveles de percepción de inseguridad por encima de la media nacional, por lo cual el estudio proporciona un acercamiento a un enclave geográfico crítico, que complementa los análisis descriptivos que pueden encontrarse con datos agregados en México.

Como primer aspecto a destacar, se encuentra que los elementos subjetivos de la seguridad ciudadana a nivel local no necesariamente replican el comportamiento nacional: mientras que los resultados de Vilalta (2012) respaldan las cinco teorías sobre percepción de inseguridad y temor al delito utilizando datos nacionales, en Acapulco la única que explica de manera contundente el fenómeno es la teoría de las incivilidades, y en particular, la presencia de conductas antisociales o delictivas en el entorno, un resultado encontrado previamente en dicho municipio por Basilio, Quintero y Méndez (2019); de igual modo, las teorías que explican el fenómeno en una determinada región no necesariamente lo harán en otra distinta, de ahí que estudios como el de Ávila et al. en el Estado de México (2015) o el de Ávila et al. en Morelos (2016) validen la teoría de la victimización, mientras que dicha explicación solo encuentra evidencia parcial al revisarse en Acapulco.

La interacción entre el deterioro del espacio público y los niveles subjetivos de seguridad ciudadana ha sido abordada en otros contextos urbanos locales de México, validando de manera importante la teoría de las incivilidades. Por ejemplo, el trabajo de Zavala (2012) caracteriza las condiciones de la vivienda popular, equipamiento urbano y espacios de interacción comunitaria en la ciudad de Tijuana, como elementos que inducen tensión e incertidumbre entre la población, provocando múltiples problemas sociales como la violencia y delincuencia; estudios como los de Villasís y Moreno (2012; 2017) y Moreno, Cárdenas y Villasís (2015), por otro lado, vinculan las particularidades urbanísticas y socioespaciales como el abandono o estigmatización de barrios, la urbanización acelerada o desordenada, y el deterioro del espacio público, al aumento de la percepción de inseguridad y la generación de una 'arquitectura del miedo' mediante espacios habitacionales cerrados o espacialmente fragmentados de la mancha urbana, tomando como estudio de caso la ciudad de San Luis Potosí; también Galeana (2018) encuentra en los municipios de Poza Rica y Coatzintla, en el estado de Veracruz, que las condiciones precarias de vivienda, espacios públicos y servicios básicos, determinan la percepción de inseguridad. En el caso de Acapulco, el presente trabajo reveló que, a pesar de presentar múltiples expresiones de deterioro de imagen urbana, éstas no inciden en la percepción general de inseguridad, pero sí en la modificación de comportamientos por temor a ser víctima de un delito.

La confianza en las autoridades locales es otro elemento fundamental para la teoría de las incivilidades, ya que la desconfianza en las instituciones de seguridad y justicia incrementa los niveles de percepción de inseguridad y temor al delito. En el análisis realizado, este componente se encuentra presente en la variable confianza institucional, la cual contiene de manera agregada la confianza en la policía municipal, estatal, federal y ministerial, fuerzas armadas (ejército y marina), jueces, ministerios públicos, cárceles y reclusorios (véase anexo 1). Si bien el estudio internacional de Singer et al. (2019) demuestra que la confianza en las instituciones del sistema de justicia penal reduce el temor al 
delito, en el caso particular de Acapulco esta relación no se presenta, aunque, por otro lado, sí produce un efecto favorable en la percepción de seguridad.

Otro resultado particular a la luz del marco teórico propuesto, es que ni la victimización directa ni la indirecta influyen en la percepción general de inseguridad; una explicación común de esta paradoja sería la normalización social de la violencia y delincuencia en la localidad bajo estudio, hipótesis que podrían atender estudios posteriores. Por otro lado, la experiencia de victimización sí incide en la modificación de comportamientos cotidianos y la implementación de medidas de autoprotección.

La discusión sobre el papel de la vulnerabilidad arroja resultados acordes con los postulados teóricos: las mujeres son más propensas a percibir una inseguridad general en diversos entornos cotidianos, mientras que la modificación de comportamientos por el temor específico a ser víctima de algún delito es más frecuente en personas con mayor edad, en mujeres, y en hogares con bajos niveles de ingreso. $\mathrm{Si}$ bien la vulnerabilidad física por cuestión de género comienza a ser controversial en la literatura, todas las mediciones de percepción de inseguridad de los últimos siete años en la ENSU muestran que las mujeres se sienten más inseguras que los hombres. En términos de vulnerabilidad social, no obstante, llama la atención que algunos componentes del perfil sociodemográfico de los habitantes de Acapulco no incidan en la construcción subjetiva de la inseguridad ciudadana, como el grado de marginación de la vivienda, el nivel educativo o la auto adscripción como indígena o afrodescendiente.

Finalmente, el escaso soporte empírico que encuentra la teoría de las redes sociales en Acapulco cuenta con un antecedente notable en el trabajo de Valle (2019), quien documenta las dificultades para la construcción de mecanismos de cohesión y contraloría social para la prevención de las violencias, desde la perspectiva de las organizaciones de la sociedad civil. En el presente trabajo, la cohesión social no resultó ser un atributo relevante para comprender por qué las personas se sienten inseguras en entornos cotidianos, ni por qué modifican comportamientos cotidianos por temor a ser victimizados.

\section{Conclusión}

Si bien los estudios sobre percepción de inseguridad y temor al delito con información nacional brindan orientación sobre la situación prevaleciente en el país, los estudios locales permiten profundizar en la comprensión del fenómeno en contextos sociales, económicos y culturales diversos. En este estudio, se abordó el caso de Acapulco, Guerrero, un municipio afectado por niveles de violencia criminal que lo posicionaron como uno de los centros urbanos más violentos del mundo en los últimos años.

Si bien la literatura sugiere cinco marcos teóricos para explicar la construcción subjetiva de la inseguridad y el temor, en este trabajo se evidenció que la comprobación empírica de sus determinantes es sensible a la estrategia de medición del fenómeno. De todos los factores propuestos, el que parece explicar en mayor medida la percepción de inseguridad y el temor al delito son las conductas antisociales o delictivas en el entorno, un elemento postulado por la teoría de las incivilidades; por otro lado, la victimización no resultó significativa para explicar la percepción de inseguridad, pero sí el temor al delito, sobre todo cuando se trata de tomar decisiones sobre las medidas de seguridad de la vivienda. Este hallazgo respalda las deducciones de Hunter (1978), respecto a que el desorden social es un factor que puede incidir en los efectos subjetivos de la inseguridad de las personas más que la propia victimización. 
Los hallazgos del estudio muestran también que la vulnerabilidad física por condición de género puede explicar tanto la percepción de inseguridad y el temor al delito, mientras que la vulnerabilidad social influye solamente al temor en sectores de la población con bajos ingresos y en hogares con jefa de familia. La confianza institucional e interpersonal son elementos que contribuyen a una menor percepción de inseguridad, pero que no inciden en el temor al delito.

Las implicaciones de esta investigación sobre las políticas de seguridad ciudadana conllevan distinguir la naturaleza del componente subjetivo y las particularidades de su parte general y específica; por un lado, las personas se sienten inseguras por conductas antisociales y delictivas que ocurren en su entorno (independientemente de si fueron víctimas de algún delito), y por una baja confianza institucional e interpersonal, con mayor intensidad en mujeres que en hombres; por otro lado, el temor al delito también se detona por conductas antisociales o delictivas en su entorno, pero también por la victimización directa e indirecta, y por algunas condiciones de vulnerabilidad social. De este modo, políticas de contención que reduzcan la incidencia delictiva no necesariamente se traducen en que las personas se sientan más seguras en términos generales, aunque sí disminuye el temor específico a ser víctimas de algún delito; o bien, acciones específicas para mejorar la confianza en las instituciones de seguridad y justicia podrían disminuir la percepción global de inseguridad, pero no afectarán al temor específico de sufrir un delito.

La única política pública que pudiera atender ambas partes del fenómeno de manera simultánea, según los hallazgos del presente trabajo, es la contención de conductas antisociales o delictivas que provocan un entorno de incivilidad en las colonias o barrios, como el consumo de alcohol en la calle, la existencia de pandillas, peleas entre vecinos, venta ilegal de alcohol, venta de productos pirata, violencia policiaca contra ciudadanos, invasión de predios, venta o consumo de droga, vandalismo, disparos o prostitución, por mencionar algunas.

Una limitación importante de estos hallazgos es que se limitan al contexto presente en Acapulco, por lo cual se recomienda que estudios posteriores aborden dicha problemática en otras demarcaciones urbanas del país caracterizadas también con una alta incidencia delictiva y violencia criminal, con el fin de discernir si también siguen estas tendencias o responden de manera diferenciada en función de sus circunstancias sociales, económicas y culturales.

\section{Referencias}

Arteaga, N. y Fuentes, R. (2009). Nueva lógica de la seguridad en México: vigilancia y control de lo público y lo privado. Revista Argentina de Sociología, 7(12-13), 164-185.

Ávila, M. E., Martínez-Ferrer, B., Vera, J. A., Bahena, A. y Musitu, G. (2015). Victimización, miedo al delito y cambios en las rutinas cotidianas en un contexto de alta criminalidad, en función del género. Revista Española de Investigación Criminológica, (13), 1-22.

Ávila, M. E., Martínez-Ferrer, B., Vera, J. A., Bahena, A. y Musitu, G. (2016). Victimización, percepción de inseguridad y cambios en las rutinas cotidianas en México. Revista de Saúde Pública, (50), 1-9. https://doi.org/10.1590/S1518-8787.2016050006098 
Basilio, B. B., Quintero, D. M. y Méndez, M. E. (2019). Percepción de inseguridad en jóvenes de colonias con altos indicadores de violencia en Acapulco, el caso del Cetis 116. En S. De la Vega, R. Rózga y G. Hoyos (coord.), Desigualdad socio-espacial, innovación tecnológica y procesos urbanos (pp. 269-282). Universidad Nacional Autónoma de México, Asociación Mexicana de Ciencias para el Desarrollo Regional A.C. http://ru.iiec.unam.mx/id/eprint/4757

Becerra, M. y Trujano, P. (2011). Percepción de inseguridad pública y justificación de la violencia de Estado en un grupo de habitantes del Estado de México: análisis de argumentos. Acta Colombiana de Psicología, 14(2), 35-43.

Buil, D. (2016). Introducción al estudio del miedo al delito: principios teóricos. Archivos de Criminología, Seguridad Privada y Criminalística, 4(7), 42-55.

Carro, D., Valera, S. y Vidal, T. (2010). Perceived insecurity in the public space: personal, social and environmental variables. Quality and Quantity, 44(2), 303-314. https://doi.org/10.1007/s11135-0089200-0

Centro de Estudios Sociales y de Opinión Pública. (2017). Seguridad y Justicia: incidencia delictiva, percepción de inseguridad, procesos judiciales y sistema penitenciario en México. Cámara de Diputados. Recuperado el 15 de agosto de 2020. http://www5.diputados.gob.mx/index.php/camara/ Centros-de-Estudio/CESOP/Estudios-e-Investigaciones/Estudios/Seguridad-y-Justicia.-Incidencia-delictiva-percepcion-de-inseguridad-procesos-judiciales-y-sistema-penitenciario-en-Mexico

Córdova, M. (2007). Percepción de inseguridad: una aproximación transversal (Tema central). En Ciudad segura. Programa de Estudios de la Ciudad. Percepción inseguridad ciudadana (pp. 4-9). Facultad Latinoamericana de Ciencias Sociales Ecuador.

Dammert, L. (2007). Entre el temor difuso y la realidad de la victimización femenina en América Latina. En A. Falú y O. Segovia (eds.), Ciudades para convivir: sin violencias hacia las mujeres (pp. 89-107). Ediciones SUR.

Ferraro, K. (1995). Fear of crime: interpreting victimization risk. State University of New York Press.

Ferraro, K. y LaGrange, R. (1987). The measurement of fear of crime. Sociological Inquiry, 57(1), 70-97. Föhrig, A. (2006). Introducción. En J. Varat y A. Garland (eds.), Participación ciudadana y percepción de inseguridad en América Latina (pp. 1-3). Woodrow Wilson International Center for Scholars.

Galeana, S. (2018). Percepción de seguridad en espacios públicos de conjuntos habitacionales de interés social: Poza Rica y Coatzintla, 2000 a 2016. Revista de urbanismo, (38), 1-14. https://doi. org/10.5354/0717-5051.2018.47084

Hale, C. (1996). Fear of crime. A review of the literature. International Review of Victimology, 4(2), 79150.

Hunter, A. (1978). Symbols of incivility: social disorder and fear of crime in urban neighborhoods. Department of Justice, National Criminal Justice Reference Service. https://www.ncjrs.gov/pdffiles1/ nij/82421.pdf

Jasso, C. (2013). Percepción de inseguridad en México, Revista Mexicana Opinión Pública, (15), 13-29. http://dx.doi.org/10.1016/S1870-7300(13)72319-6

Kessler, G. (2009). El sentimiento de inseguridad. Sociología del temor al delito. Siglo XXI.

Kessler, G. y Focás, B. (2014). ¿Responsables del temor? Medios y sentimiento de inseguridad en América Latina. Nueva Sociedad, (249), 137-148. 
Martínez-Ferrer, B., Ávila-Guerrero, M. A., Vera-Jiménez, J. A., Bahena-Rivera, A. y Musitu-Ochoa, G. (2016). Satisfacción con la vida, victimización y percepción de inseguridad en Morelos, México. Salud Pública de México, 58(1), 16-24.

Moreno, A., Cárdenas, A. y Villasís, R. (2015). Periurbanidad, desigualdad y segregación en San Luis Potosí, 1990-2010. Observatorio del Desarrollo. Investigación, reflexión y análisis, 4(14), 63-70.

Ruiz, J. I. (2007). Cultura ciudadana, miedo al crimen y victimización: un análisis de sus interrelaciones desde la perspectiva del tejido social. Acta Colombiana de Psicología, 10(1), 65-74.

Salado, M., Quintero, D. y Arziga, J. (2018). La percepción de seguridad, implicaciones en el desarrollo de capacidades de estudiantes de educación superior en Acapulco, Guerrero. En S. De la Vega y C. Ken (coord.), Condiciones sociales, empobrecimiento y dinámicas regionales de mercados laborales (pp. 63-79). Universidad Nacional Autónoma de México, Asociación Mexicana de Ciencias para el Desarrollo Regional A.C. http://ru.iiec.unam.mx/id/eprint/4354

Singer, A., Chouhy, C., Lehmann, P., Walzak, J., Gertz, M. y Biglin, S. (2019). Victimization, fear of crime, and trust in criminal justice institutions: a cross-national analysis. Crime and Delinquency, 65(6), 822-844. https://doi.org/10.1177/0011128718787513

Triana, J. (2017). Percepción de inseguridad en polígonos geográficos prioritarios en Acapulco. Espiral Estudios Sobre Estado y Sociedad, 24(70), 221-249. http://dx.doi.org/10.32870/espiral.v24i70.5786

Triana, J., Del Carmen, R., Esparza, J. C., y Santos, C. (2019). Informe sobre seguridad ciudadana en Acapulco. Incidencia delictiva, percepción de inseguridad, factores de riesgo y políticas de prevención. Universidad Autónoma de Guerrero. https://doi.org/10.5281/zenodo.4339215

Valle, P. (2019). La violencia en Acapulco desde la sociedad civil: mecanismos de cohesión y contraloría social. Intersticios Sociales, (18), 169-211.

Varela, F. y Schwaderer, H. (2010). Determinantes del temor al delito en Chile. Fundación Paz Ciudadana. Recuperado el 10 de agosto de 2020. https://biblioteca.cejamericas.org/bitstream/handle/2015/1767/temor.pdf?sequence $=1 \&$ isAllowed $=y$

Vilalta, C. (2010). El miedo al crimen en México. Estructura lógica, bases empíricas y recomendaciones iniciales de política pública. Gestión y Política Pública, 19(1), 3-36.

Vilalta, C. (2012). Los determinantes de la percepción de inseguridad frente al delito en México. Documento de trabajo del BID \#IDB-WP-381, Banco Interamericano de Desarrollo. Recuperado el 12 de agosto de 2020. https://publications.iadb.org/publications/spanish/document/Los-determinantesde-la-percepción-de-inseguridad-frente-al-delito-en-México.pdf

Villasís, R. y Moreno, A. (2012). Ciudades seguras, exclusión socioespacial y gobernanza para la seguridad en ciudades medias de México: situación actual y tendencias en la Zona Metropolitana de San Luis Potosí. En Memorias del Congreso Internacional de Planificación y Estudios Urbanos: Desafíos de la planificación ante la creciente complejidad urbana (pp. 145-167). Universidad Autónoma de Ciudad Juárez,

Villasís, R. y Moreno, A. (2017). La irrupción de la inseguridad en la reconfiguración del paisaje urbano. Ponencia en el X Congreso Nacional de Arquitectura de Paisaje: Paisajes Disruptivos. El paisaje, herramienta para el cambio. Universidad Autónoma de San Luis Potosí.

Vozmediano, L. (2010). Percepción de inseguridad y conductas de autoprotección: propuestas para una medición contextualizada del miedo al delito. Eguzkilore, (24), 203-237. 
- Revista de Ciencias Sociales y Humanidades. ISSN-P: 0188-9834 ISSN-E:2395-8669.

Vozmediano, L., San Juan, C. y Vergara, A. I. (2008). Problemas de medición del miedo al delito. Algunas respuestas teóricas y técnicas. Revista Electrónica de Ciencia Penal y Criminología, (10), 1-17.

Vozmediano, L., Vergara, A. I. y San Juan, C. (2010). El estudio científico del miedo al delito: algunas reflexiones sobre un fenómeno urbano, mediático y político. International E-Journal of Criminal Sciences, (4), 1-20.

Wooldridge, J. (2015). Introducción a la econometría. Cengage Learning.

Zavala, L. (2012). El problema habitacional de Tijuana. En S. López (coord.), La realidad social y las violencias. Zona metropolitana de Tijuana (pp. 79-108). El Colegio de la Frontera Norte, Incide Social. 


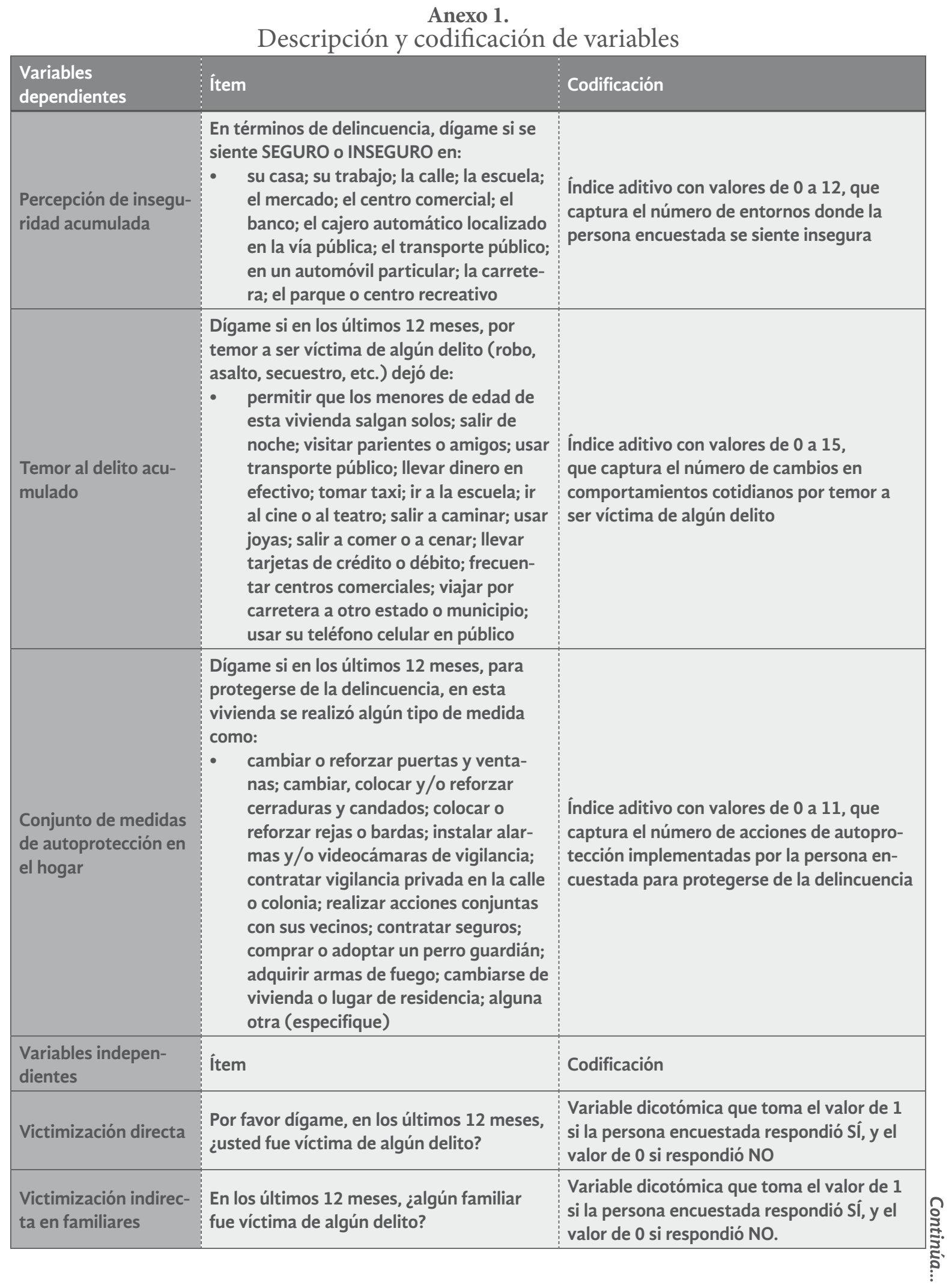


Revista de Ciencias Sociales y Humanidades. ISSN-P: 0188-9834 ISSN-E:2395-8669.

\begin{tabular}{|c|c|c|}
\hline $\begin{array}{l}\text { Variables } \\
\text { dependientes }\end{array}$ & İtem & Codificación \\
\hline $\begin{array}{l}\text { Victimización indirec- } \\
\text { ta en vecinos }\end{array}$ & $\begin{array}{l}\text { En los últimos } 12 \text { meses, ¿algún vecino fue } \\
\text { víctima de algún delito? }\end{array}$ & $\begin{array}{l}\text { Variable dicotómica que toma el valor de } 1 \\
\text { si la persona encuestada respondió Sí, y el } \\
\text { valor de } 0 \text { si respondió NO }\end{array}$ \\
\hline $\begin{array}{l}\text { Victimización indi- } \\
\text { recta en amigos o } \\
\text { conocidos }\end{array}$ & $\begin{array}{l}\text { En los últimos } 12 \text { meses, ¿algún amigo o } \\
\text { conocido fue víctima de algún delito? }\end{array}$ & $\begin{array}{l}\text { Variable dicotómica que toma el valor de } 1 \\
\text { si la persona encuestada respondió Sí, y el } \\
\text { valor de } 0 \text { si respondió NO }\end{array}$ \\
\hline Edad & ¿Cuántos años tiene? & $\begin{array}{l}\text { Variable numérica que captura la edad de la } \\
\text { persona encuestada }\end{array}$ \\
\hline Sexo & Sexo del encuestado & $\begin{array}{l}\text { Variable dicotómica que toma el valor de } 1 \\
\text { si la persona es HOMBRE, y el valor de } 0 \text { si } \\
\text { es MUJER }\end{array}$ \\
\hline $\begin{array}{l}\text { Ingreso per cápita es- } \\
\text { timado en la vivienda }\end{array}$ & $\begin{array}{l}\text { ¿Cuántas personas viven normalmente } \\
\text { en esta vivienda, contando a los niños } \\
\text { chiquitos y a los ancianos? } \\
\text { Si sumara el ingreso mensual de todas las } \\
\text { personas que viven aquí, ¿en qué letra se } \\
\text { ubicaría esta vivienda, aproximadamente? }\end{array}$ & $\begin{array}{l}\text { Variable ordinal con valores del } 1 \text { al } 6 \text {, que } \\
\text { se calcula dividiendo el promedio de los } \\
\text { valores mínimos y máximos del ingreso } \\
\text { mensual en la vivienda señalado por la per- } \\
\text { sona encuestada, y el número de habitantes } \\
\text { en dicha vivienda; el resultado se categoriza } \\
\text { en los siguientes intervalos: } \\
1: \$ 600 \text { o menos } \\
2: \text { de } \$ 601 \text { a } \$ 1,200 \\
3: \text { de } \$ 1,201 \text { a } \$ 1,800 \\
4: \text { de } \$ 1,801 \text { a } \$ 2,400 \\
5: \text { de } \$ 2,401 \text { a } \$ 3,000 \\
6: \$ 3,001 \text { o más }\end{array}$ \\
\hline $\begin{array}{l}\text { Grado de margina- } \\
\text { ción }\end{array}$ & $\begin{array}{l}\text { ¿De qué material es la mayor parte del piso } \\
\text { de esta vivienda? } \\
\text { ¿De qué material es la mayor parte de las } \\
\text { paredes externas de esta vivienda? } \\
\text { ¿De qué material es la mayor parte del } \\
\text { techo de esta vivienda? }\end{array}$ & $\begin{array}{l}\text { Variable dicotómica que toma el valor de } \\
1 \text { si la vivienda cuenta con piso de tierra, } \\
\text { paredes de lámina/cartón, adobe o material } \\
\text { de desecho, o techo de lámina/cartón o } \\
\text { material de desecho; toma el valor de } 0 \text { en } \\
\text { caso contrario. }\end{array}$ \\
\hline Nivel educativo & ¿Hasta qué nivel aprobó en la escuela? & $\begin{array}{l}\text { Variable ordinal que agrupa el nivel educati- } \\
\text { vo en los siguientes valores: } \\
\text { 1: Ninguno o preescolar } \\
\text { 2: Primaria } \\
\text { 3: Secundaria } \\
\text { 4: Preparatoria/bachillerato, carrera técnica } \\
\text { con secundaria terminada, o normal básica } \\
\text { con secundaria terminada } \\
\text { 5: Licenciatura/profesional o posgrado }\end{array}$ \\
\hline $\begin{array}{l}\text { Auto adscripción } \\
\text { indígena }\end{array}$ & $\begin{array}{l}\text { De acuerdo con sus costumbres y tradicio- } \\
\text { nes, ¿usted se considera indígena? }\end{array}$ & $\begin{array}{l}\text { Variable dicotómica que toma el valor de } 1 \\
\text { si la persona encuestada respondió Sí, y el } \\
\text { valor de } 0 \text { si respondió NO. }\end{array}$ \\
\hline $\begin{array}{l}\text { Auto adscripción } \\
\text { afrodescendiente }\end{array}$ & $\begin{array}{l}\text { De acuerdo con sus costumbres y tradicio- } \\
\text { nes, ¿usted se considera negro o afrodes- } \\
\text { cendiente? }\end{array}$ & $\begin{array}{l}\text { Variable dicotómica que toma el valor de } 1 \\
\text { si la persona encuestada respondió Sí, y el } \\
\text { valor de } 0 \text { si respondió NO. }\end{array}$ \\
\hline
\end{tabular}


- Revista de Ciencias Sociales y Humanidades. ISSN-P: 0188-9834 ISSN-E:2395-8669.

\begin{tabular}{|c|c|c|}
\hline $\begin{array}{l}\text { Variables } \\
\text { dependientes }\end{array}$ & Îtem & Codificación \\
\hline $\begin{array}{l}\text { Hogar con jefa de } \\
\text { familia }\end{array}$ & $\begin{array}{l}\text { La persona que sostiene económicamente } \\
\text { este hogar, ¿es hombre o mujer? } \\
\text { (¿O ambos sexos sostienen el hogar por } \\
\text { igual?) }\end{array}$ & $\begin{array}{l}\text { Variable dicotómica que toma el valor de } 1 \\
\text { si la persona encuestada respondió MUJER, } \\
\text { y el valor de } 0 \text { si respondió HOMBRE o } \\
\text { AMBOS. }\end{array}$ \\
\hline $\begin{array}{l}\text { Deterioro de imagen } \\
\text { urbana }\end{array}$ & $\begin{array}{l}\text { En los últimos } 12 \text { meses, dígame si ha visto } \\
\text { en los alrededores de su vivienda: } \\
\text { carros abandonados; terrenos baldíos; } \\
\text { casas o edificios abandonados; par- } \\
\text { ques o canchas deportivas deterio- } \\
\text { radas; paradas de transporte público } \\
\text { deterioradas; fachadas deterioradas } \\
\text { de casas o edificios; conexiones eléc- } \\
\text { tricas irregulares (gente colgada de la } \\
\text { luz con diablitos); perros callejeros u } \\
\text { otros animales en abandono; comercio } \\
\text { informal o ambulante }\end{array}$ & $\begin{array}{l}\text { Îndice aditivo con valores de } 0 \text { a } 9 \text {, que } \\
\text { captura el número de elementos de } \\
\text { deterioro de imagen urbana que reporta la } \\
\text { persona encuestada }\end{array}$ \\
\hline $\begin{array}{l}\text { Conductas antisocia- } \\
\text { les o delictivas en el } \\
\text { entorno }\end{array}$ & $\begin{array}{l}\text { ¿Sabe usted o ha escuchado si en los } \\
\text { alrededores de su vivienda, en los últimos } \\
12 \text { meses, se han presentado las siguientes } \\
\text { situaciones? } \\
\text { - Se consume alcohol en la calle; existe } \\
\text { pandillerismo o bandas violentas; hay } \\
\text { peleas entre vecinos; existe venta } \\
\text { ilegal de alcohol; se venden productos } \\
\text { piratas; ha habido violencia policiaca } \\
\text { contra ciudadanos; hay invasión de } \\
\text { predios; se vende y/o consume droga; } \\
\text { existen robos o asaltos; vandalismo } \\
\text { (grafitis, pintas, vidrios quebrados, } \\
\text { etc.); ha habido disparos; hay prosti- } \\
\text { tución; ha habido secuestros; ha habi- } \\
\text { do homicidios; ha habido extorsiones } \\
\text { (o cobro de piso) }\end{array}$ & $\begin{array}{l}\text { Îndice aditivo con valores de } 0 \text { a } 15 \text {, que } \\
\text { captura el número de conductas antisociales } \\
\text { o delictivas que reporta la persona } \\
\text { encuestada }\end{array}$ \\
\hline $\begin{array}{l}\text { Grado de cohesión } \\
\text { social }\end{array}$ & $\begin{array}{l}\text { La gente en ocasiones se llega a reunir } \\
\text { para realizar actividades comunes; en una } \\
\text { escala del } 1 \text { al 5, donde } 1 \text { es NADA FRE- } \\
\text { CUENTE y } 5 \text { es MUY FRECUENTE dígame } \\
\text { con qué frecuencia se reúnen en su colonia: } \\
\text { para eventos religiosos; para organi- } \\
\text { zar fiestas; para solucionar problemas } \\
\text { de servicios como agua, alumbrado, } \\
\text { pavimentación o limpieza; para } \\
\text { organizar la seguridad de la colonia; } \\
\text { para solicitar servicios del municipio; } \\
\text { para convivir casualmente en un área } \\
\text { común o pública (patio, jardín, calle, } \\
\text { salón, etc.); con otro objetivo (espe- } \\
\text { cifique) }\end{array}$ & $\begin{array}{l}\text { Índice que toma valores continuos del } 1 \text { a } \\
5 \text {, que se calcula como el promedio de las } \\
\text { frecuencias de reunión reportadas por la } \\
\text { persona encuestada }\end{array}$ \\
\hline
\end{tabular}


- Revista de Ciencias Sociales y Humanidades. ISSN-P: 0188-9834 ISSN-E:2395-8669.

\begin{tabular}{|c|c|c|}
\hline $\begin{array}{l}\text { Variables } \\
\text { dependientes }\end{array}$ & Ítem & Codificación \\
\hline $\begin{array}{l}\text { Confianza institu- } \\
\text { cional }\end{array}$ & $\begin{array}{l}\text { Por favor dígame, en una escala del } 1 \text { al } 5 \\
\text { donde } 1 \text { es NADA DE CONFIANZA y } 5 \text { es } \\
\text { MUCHA CONFIANZA, qué tanto confía en: } \\
\text { la policía municipal; la policía estatal; } \\
\text { la policía federal; la policía ministerial; } \\
\text { los maestros; la marina; el ejército; } \\
\text { el ministerio público; los jueces; las } \\
\text { cárceles y reclusorios }\end{array}$ & $\begin{array}{l}\text { Índice que toma valores continuos del } 1 \text { a } \\
5 \text {, que se calcula como el promedio de la } \\
\text { confianza institucional reportada por la } \\
\text { persona encuestada }\end{array}$ \\
\hline $\begin{array}{l}\text { Confianza interper- } \\
\text { sonal }\end{array}$ & $\begin{array}{l}\text { En la misma escala, por favor dígame qué } \\
\text { tanto confía en: } \\
\text { sus vecinos; sus compañeros de traba- } \\
\text { jo/negocio; sus familiares o parientes; } \\
\text { en los compañeros de la escuela/ } \\
\text { padres de familia; sus amigos; en } \\
\text { general, en las demás personas }\end{array}$ & $\begin{array}{l}\text { Índice que toma valores continuos del } 1 \text { a } \\
5 \text {, que se calcula como el promedio de la } \\
\text { confianza interpersonal reportada por la } \\
\text { persona encuestada }\end{array}$ \\
\hline
\end{tabular}

Fuente: elaboración propia, con ítems de la ESCA 2019 